\title{
sala \\ de

\section{CONVITE À FORMULAÇÃO DE PROBLEMAS DE MULTIPLICAÇÃO E DIVISÃO NO EIXO PRODUTOS DE MEDIDAS: UM PASSEIO À LANCHONETE}

\author{
AN INVITATION A PROBLEM-POSING OF MULTIPLICATION AND DIVISION IN THE PRODUCT AXIS \\ MEASURES: A VISIT TO A CAFETERIA \\ Renan Oliveira Altoé \\ Centro Educacional São Camilo - ES \\ E-mail: renan.o.altoe@gmail.com \\ Rony Cláudio de Oliveira Freitas \\ Instituto Federal do Espírito Santo, Campus Vitória \\ E-mail: freitasrco@gmail.com
}

\begin{abstract}
Resumo. Este relato de experiência tem por objetivo apresentar análises de uma proposta de Formulação de Problemas, intitulada "Um passeio à lanchonete", que pode contribuir para o ensino das operações de multiplicação e divisão, no Campo Conceitual Multiplicativo, na classe de Combinatória. A proposta foi desenvolvida em uma pesquisa de Mestrado em Educação em Ciências e Matemática, seguindo pressupostos metodológicos da Engenharia Didática, em um estudo qualitativo, cujos dados foram produzidos no 5o de uma Escola Estadual do Município de Vargem Alta - ES. As análises evidenciaram que a proposta é potencialmente significativa nos estudos dessas operações, uma vez que envolveu os estudantes na formulação de problemas de raciocínio combinatório, levando-os a refletir sobre a multiplicação e divisão. As produções podem ser utilizadas, pelo professor, nas aulas de matemática, pois carregam consigo motivações intrínsecas, fatores que podem entusiasmar os alunos na resolução de problemas.
\end{abstract}

Palavras-chave: Formulação de problemas. Campo conceitual multiplicativo. Multiplicação e divisão.

\begin{abstract}
This work aims to report and analyze the experience of a Problem Formulation proposal entitled $A$ visit to the cafeteria. This experience can contribute to the teaching of multiplication and division operations in the Multiplicative Conceptual Field. The proposal was developed in a master's research in Science and Mathematics Education, following methodological assumptions of Didactic Engineering, in a qualitative study. The data analyzed here were generated in a 5th-grade class, from elementary school, from a State School in the Municipality of Vargem Alta - ES. The analyses showed that the proposal is potentially significant in the studies of these operations, since it involved students in the problem-posing of combinatorial reasoning, leading them to reflect on the multiplication and division. The teacher can use these productions in mathematics classes because they carry with them intrinsic motivations, factors that can excite students in solving problems.
\end{abstract}

Keywords: Problem-Posing. Multiplicative Conceptual Field. Multiplication and division. 


\section{sala \\ de $\oplus$ - em \\ aula foco}

-REVISTA ELETRÔNICA

\section{INTRODUÇÃO}

A escola se constitui como um espaço de produção de conhecimentos onde é fundamental o envolvimento dos estudantes na promoção da aprendizagem e no desenvolvimento do estímulo à reflexão crítica. Observar o mundo real e buscar correlacioná-lo com conceitos matemáticos se torna, cada vez mais, um fator de importância na aprendizagem matemática. Nessa perspectiva, temos defendido que a Formulação de Problemas $^{1}$ pode contribuir para a formação de conceitos matemáticos, por meio da reflexão crítico-investigativa, levando os estudantes a expressarem seus conhecimentos durante o processo de formulação e nos próprios problemas formulados.

Sendo assim, neste trabalho, apresentamos análises de uma proposta de Formulação de Problemas, intitulada "Um passeio à lanchonete", que pode contribuir para o ensino de multiplicação e divisão, no Campo Conceitual Multiplicativo, na classe de Combinatória. A proposta foi desenvolvida em uma pesquisa de Mestrado em Educação em Ciências e Matemática do Ifes, Campus Vitória - ES, seguindo pressupostos metodológicos da Engenharia Didática, em um estudo qualitativo.

\section{FORMULAÇÃO DE PROBLEMAS: BREVES APONTAMENTOS}

A formulação de problemas, nas aulas de matemática, é um modo de ampliar o protagonismo discente nas aulas de matemática e ajudá-los a refletir sobre seus conhecimentos matemáticos e a exprimirem seu pensamento, gerando descobertas e motivação. Para Silver (1994, p. 19, tradução nossa), formular problemas "[...] refere-se tanto a produção de novos problemas e a reformulação de determinados problemas". Nas aulas de matemáticas "as crianças podem inventar os próprios problemas. Isso as motivará a ler, compreender e resolver os problemas, porque são seus" (DANTE, 2009, p. 65). Para Altoé (2017) formular problemas requer, inicialmente, conhecer conceitos,

\footnotetext{
${ }^{1}$ Neste texto, utilizamos "Formulação de Problemas" quando tratamos da prática no campo teórico, e "formulação de problemas" a ação de formular o problema em sala de aula.
}

Revista Eletrônica Sala de Aula em Foco, ISSN 2316-7297 - Volume 8, Número 2, 23-36, 2019 


\section{sala \\ de $\oplus$ - em \\ aula foco}

-REVISTA ELETRÔNICA

refletir sobre situações inquietadoras ou desafiadoras, entender o porquê do que estou pretendendo formular.

No processo de formular problemas, o aluno participa ativamente de um fazer em matemática que desenvolve, para além da linguagem, o interesse e a confiança em seu modo de pensar (DINIZ, 2001). Com isso, "quando o aluno cria seus próprios textos de problemas, ele precisa organizar tudo o que sabe [...], dando-Ihe sentido a estrutura adequada para que possa comunicar o que pretende" (CHICA, 2001, p. 151).

Segundo Chica (2001, p. 152), "quando um aluno formula um problema ele percebe o que é importante na elaboração e na resolução de uma situação dada; que relação há entre os dados apresentados, a pergunta a ser respondida e a resposta". Assim, "dependendo da maneira como a formulação é trabalhada, a mesma pode oportunizar os discentes a formularem problemas com contextos de seus interesses, tornando uma prática que antes era desinteressante, em momentos de inventividade e descoberta" (ALTOÉ, 2017, p. 52). Logo,

[...] é preciso estimular a capacidade inventiva e questionadora dos alunos, desenvolvendo na sala de aula um clima de interação e respeito, onde se possa fazer matemática através da possibilidade de questionar, levantar hipóteses, comunicar ideias, estabelecer relações e aplicar conceitos (CHICA, 2001, p. 153).

A manifestação da capacidade inventiva pode ser um fator que contribui no desenvolvimento da criatividade, presente tanto na formulação de problemas quanto na resolução. Assim, Silver (1994, p. 20) afirma que "formular problemas tem sido visto como uma característica de atividade criativa $[\ldots]^{\prime \prime}$.

Medeiros e Santiago (2013) e Pinheiro (2013) concluíram, em suas pesquisas, que os alunos apresentaram dificuldades na formulação de problemas e sugerem que essa prática esteja mais presente nas aulas de matemática. Nessa perspectiva, "necessitamos propor frequentemente a formulação de problemas para que nossos alunos consigam avançar elaborando, cada vez mais, problemas de melhor qualidade e coerentes" (ALTOÉ, 2017, p. 57). Enfim, formular problemas é tão importante quanto resolver problemas!

Revista Eletrônica Sala de Aula em Foco, ISSN 2316-7297 - Volume 8, Número 2, 23-36, 2019 


\section{sala \\ de $\oplus$ em \\ aula foco}

-REVISTA ELETRÔNICA

\section{MULTIPLICAÇÃO E DIVISÃO EM PRODUTO DE MEDIDAS: A CLASSE DE COMBINATÓRIA}

No Campo Conceitual Multiplicativo², em combinatória, a multiplicação é uma operação em busca de encontrar a medida-produto, conhecendo-se as medidas elementares, cujas relações se estabelecem somente entre quantidades discretas-discretas (VERGNAUD, 2014). A estrutura organizacional para esse tipo de problema é "[...] a noção de produto cartesiano de conjuntos que explica a estrutura do produto de medidas" (VERGNAUD, 2014, p. 254).

Considerando o seguinte exemplo dado por Vergnaud (2014), vejamos como a multiplicação se encaixa e produz sentido dentro desse conjunto de problemas: "3 rapazes e 4 moças querem dançar. Cada rapaz quer dançar com cada moça e cada moça, com cada rapaz. Quantos seriam os casais possíveis?" Considerando dois conjuntos $R=\{a, b, c\}$, dos rapazes, e $M=\{f, g, h, i\}$, das moças, temos:

\begin{tabular}{|c|c|c|c|c|}
\hline & $f$ & g & $h$ & i \\
\hline $\bar{a}$ & $(a, f)$ & $(a, g)$ & $(a, h)$ & $(a, i)$ \\
\hline b & $(b, f)$ & $(b, g)$ & $(b, h)$ & $(b, i)$ \\
\hline C & $(c, f)$ & $(c, g)$ & $(c, h)$ & $(c, i)$ \\
\hline
\end{tabular}

O produto cartesiano acima ( $\mathrm{R}$ X M) produz pares ordenados correspondentes à associação de cada elemento do conjunto R com cada elemento do conjunto M. Assim, o número de casais é facilmente determinado por uma multiplicação entre a quantidade de elementos dos dois conjuntos: $\mathrm{y}$ casais = 3 rapazes $\times 4$ moças.

Direcionando-nos para a divisão, esta busca encontrar medidas elementares, conhecendo-se uma delas e medida-produto, cujas relações são estabelecidas, também, entre quantidades discretas-

\footnotetext{
${ }^{2}$ O Campo Conceitual Multiplicativo ou das Estruturas Multiplicativas consiste de todas as situações que podem ser analisadas como problemas de proporções simples e múltipla para os quais geralmente é necessária uma multiplicação, uma divisão ou uma combinação dessas operações para resolvê-los (MOREIRA, 2015).
} 


\section{sala \\ de $\oplus$ - em \\ aula foco}

-REVISTA ELETRÔNICA

discretas (VERGNAUD, 2014). Considerando o problema apresentado por Vergnaud (2014), vejamos como essa operação se comporta: "Um comerciante quer colocar à disposição dos clientes 15 variedades de sorvetes cobertos de chocolate. Ele dispõe de três variedades de chocolates. Quantas variedades de sorvetes ele deve ter?" Sendo y a quantidade de variedades de sorvetes cobertos de chocolate, $z$ a quantidade de variedades de chocolates e $w$ a variedade de sorvetes. De posse desses dados, temos: 15 sorvetes cobertos de chocolate $=3$ variedades de chocolates $\times z$ variedades de sorvetes. Com isso, a divisão busca a medida elementar, ou seja, qual número multiplicado por 3 resultaria em 15? Para isso, bastaria uma divisão entre a medida-produto (o número 15) e uma das medidas (o número 3).

\section{ENGENHARIA DIDÁTICA}

A Engenharia Didática é uma metodologia de ensino-pesquisa que considera pertinente vincular a dimensão teórica da racionalidade ao campo experimental da prática educativa a fim de proporcionar o desenvolvimento da aprendizagem. Segundo Pais (2011), a partir dos estudos de Artigue (1996), essa metodologia apresenta característica de esquema experimental baseado em realizações didáticas em classe, e, segundo Almouloud e Coutinho (2008), existe a comparação entre análise a priori e análise a posteriori, realizadas na etapa de validação. De natureza qualitativa, do tipo experimental, é como entendemos a pesquisa relatada neste artigo. A Engenharia Didática adotada na pesquisa é conhecida como "clássica ou de primeira geração", proposta por Artigue. Segundo Artigue (1996, p. 247 apud PAIS, 2011, p. 104), a Engenharia Didática "[...] vista como metodologia de pesquisa, caracteriza-se, em primeiro lugar, por ser um esquema experimental baseado em realizações didáticas em classe [...]".

De acordo com Pais (2011), a Engenharia Didática segue quatro fases: 1) análises preliminares; 2) concepção e análise a priori; 3) aplicação de uma sequência didática e 4) análise a posteriori e a avaliação. Em nossa pesquisa, a terceira fase foi renomeada de "aplicação de uma sequência de atividades", visto que não propusemos uma sequência didática, rigorosamente dita, mas um grupo de propostas, em formato de história, de formulação de problemas. 


\section{sala \\ de $\oplus$ em \\ aula foco}

REVISTA ELETRÔNICA

Neste trabalho, discorremos apenas os aspectos principais das análises relativas às etapas "aplicação de uma sequência de atividades" (Etapa 3) e "análise a posteriori e a avaliação" (Etapa 4), representadas pela seção 5, a seguir.

\section{A PROPOSTA DE FORMULAÇÃO DE PROBLEMAS: ANÁLISES DA APLICAÇÃO}

A história "Um passeio à lanchonete" foi elaborada com foco para os estudos de multiplicação e divisão na classe de problemas de combinatória. Na aplicação dessa proposta, estiveram presentes 23 discentes, cujas discussões tiverem início a partir das próprias questões a serem respondidas no decorrer da história, para as quais os estudantes apresentaram algumas dificuldades inerentes à compreensão da expressão e cálculo de "contagem de possibilidades" e que foram discutidas e entendidas juntamente aos pesquisadores e a professora regente.

Percebemos um forte interesse dos envolvidos pela leitura e realização das atividades, quando se demonstraram dispostos a debater os questionamentos inerentes à história, que tem início com dois amigos indo, após a aula, a uma lanchonete que se localiza no centro da cidade de onde moram. Chegando lá, foram prontamente atendidos pelo garçom que Ihes entregou o menu do estabelecimento, no qual constavam diferentes tipos de comidas e bebidas. Porém, o menu está sem todos os registros e é perguntado aos estudantes: o que vocês acham que tinha naquele menu? Vamos completá-lo? Após esse questionamento, os participantes foram convidados a preencherem o menu considerando quaisquer produtos que eles imaginavam que estivesse a disposição para compra.

A história relata que os amigos ficaram muito entusiasmados e contentes com a diversidade de produtos presentes no menu, mas tantas opções os deixaram em dúvidas quanto ao que comer e beber. Nesse momento, surge o seguinte questionamento: vocês saberiam dizer de quantas maneiras diferentes é possivel escolher uma bebida e uma comida do menu? Quando as discussões relativas a essas questões foram finalizadas, os discentes foram convidados a formular seus problemas envolvendo o pensamento combinatório. Abaixo, na Figura 1, apresentamos a proposta.

Revista Eletrônica Sala de Aula em Foco, ISSN 2316-7297 - Volume 8, Número 2, 23-36, 2019 


\section{sala \\ de $\oplus$ em \\ aula foco}

Figura 1: Proposta de formulação de problemas

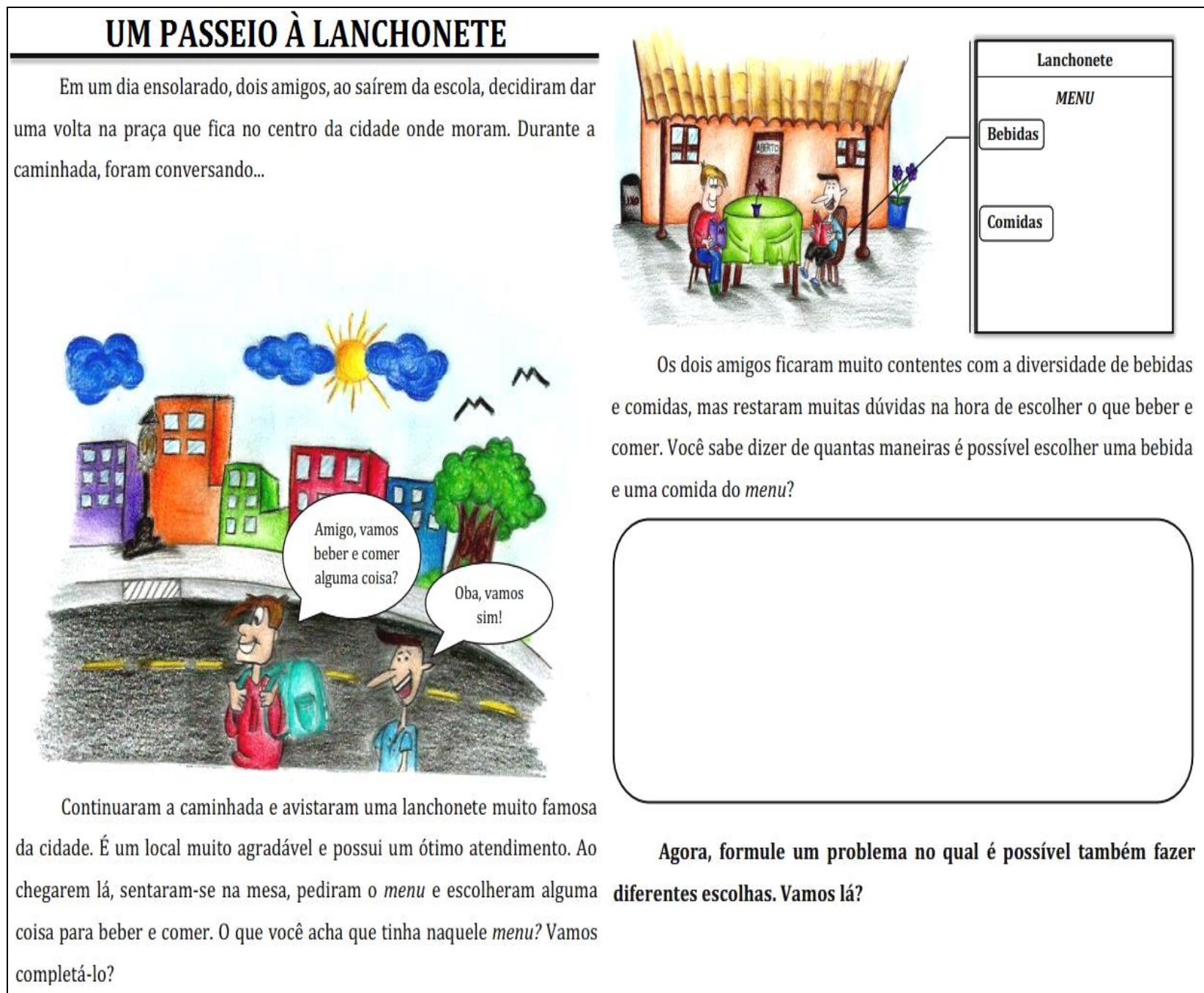

Fonte: ALTOÉ; FREITAS (2017, p. 13-14)

O primeiro questionamento - o que você acha que tinha naquele menu? Vamos completá-lo? contribuiu para que os estudantes se envolvessem na reflexão de possíveis comidas e bebidas que poderiam ser comuns a uma lanchonete. Não identificamos dificuldades nesta etapa da atividade, contudo, alguns discentes questionaram se havia uma quantidade máxima de produtos que 


\section{sala \\ de $\oplus$ em \\ aula foco}

poderiam supor ao menu e Ihes foi dito que não. Abaixo, nas Figuras 2 e 3, podemos ver a realização da atividade por A02-113 e A27-11.

Figura 2: Menu de A02-11

\begin{tabular}{|c|}
\hline Lanchonete \\
\hline MENU \\
\hline Bebidas \\
\hline 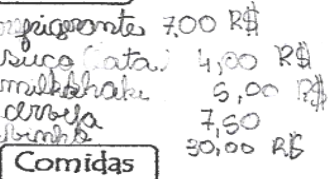 \\
\hline 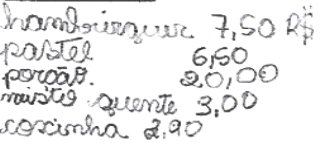 \\
\hline
\end{tabular}

Fonte: Arquivo dos autores
Figura 3: Menu de A27-11

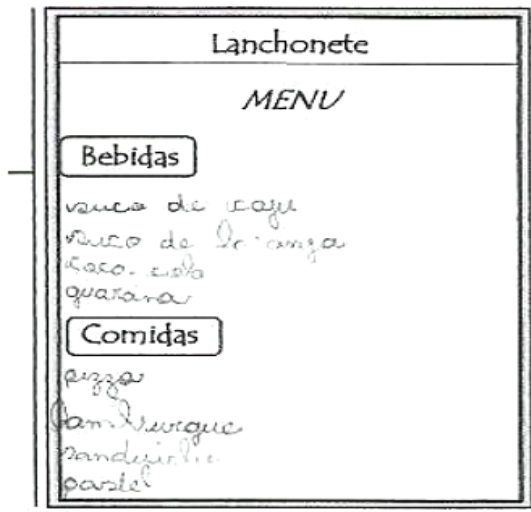

Fonte: Arquivo dos autores

Concluído o preenchimento do menu, os estudantes se envolveram com o segundo questionamento: você sabe dizer de quantas maneiras é possível escolher uma bebida e uma comida do menu? Com ele, buscamos oportunizar a reflexão a respeito de quantas maneiras distintas os amigos poderiam escolher uma bebida e uma comida naquela lanchonete, tendo por base os produtos do próprio menu que construíram na tarefa anterior. Percebemos algumas dificuldades com relação à determinação do total de maneiras distintas de se escolher uma comida e uma bebida, principalmente daqueles que construíram um menu muito extenso. Diante dessas evidências, sugerimos (pesquisador e professora regente) que os participantes relacionassem cada um dos produtos, dois a dois, em espécies diferentes. Utilizamos o esquema representativo do Diagrama da Árvore para orientar as dúvidas.

\footnotetext{
${ }^{3}$ Atendendo ao processo ético confiado na pesquisa (aprovada pelo Comitê de Ética e Pesquisa do IFES sob o no CAAE 56129916.6.0000.5072 e tendo por base a análise feita no Parecer de no 1.577.247), os alunos foram identificados pela vogal " $A$ " (de Aluno), acrescida de numeração indo-arábica (indica o número do participante), seguida da sua respectiva idade. Assim, por exemplo, o aluno A03-10 é o terceiro do total de 28 participantes, cuja idade é 10 anos.
}

Revista Eletrônica Sala de Aula em Foco, ISSN 2316-7297 - Volume 8, Número 2, 23-36, 2019 


\section{sala \\ de $\oplus$ - em \\ aula foco}

Bebida 1

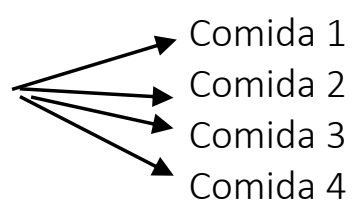

(Bebida 1 e Comida 1)

(Bebida 1 e Comida 2)

(Bebida 1 e Comida 3)

(Bebida 1 e Comida 4)

Em seguida, traduzimos essa representação em uma multiplicação, destacando que essa operação entre a quantidade de bebidas e a quantidade de comidas resultaria no total de maneiras distintas, ou seja, $1 \times 4$ = 4 possibilidades. Após essas explicações, os estudantes começaram a elaborar ${ }^{4}$ seus diagramas, quando identificamos que 6 discentes realizaram todos os esquemas que representavam as escolhas para o seu menu, 8 discentes relacionaram somente alguns casos, 8 discentes procederem diretamente a operação de multiplicação, e 1 discente não fez esta parte da atividade. Abaixo, apresentaremos um exemplo dessas discussões.

Figura 4: Diagrama e resolução numérica de A05-10

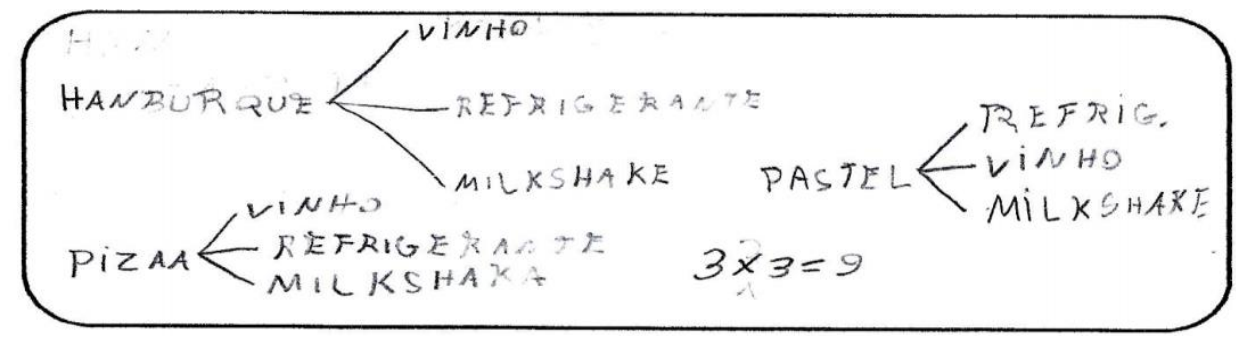

Fonte: Arquivo dos autores

Quando concluíram as questões decorrentes da história, os alunos iniciaram o processo de formulação de problemas a partir do seguinte comando existente na história: Agora, formule um problema no qual é possível também fazer diferentes escolhas. Vamos lá? Não demorou muito para que as primeiras propostas fossem elaboradas e apresentassem características de situações envolvendo combinatória. Evidentemente, uma parte da turma necessitou de ajuda na formulação,

${ }^{4}$ É outra maneira de se referir a formular problemas, assim como: gerar, criar ou produzir.

Revista Eletrônica Sala de Aula em Foco, ISSN 2316-7297 - Volume 8, Número 2, 23-36, 2019 


\section{sala \\ de $\rightarrow$ em \\ aula foco}

principalmente com respeito à escolha do contexto ${ }^{5}$, pois não tinham certeza de que ele serviria para elaborar um problema de combinatória. Nossas análises identificaram 23 problemas formulados, dos quais 19 apresentaram o raciocínio combinatório. Abaixo, na Figura 5, apresentamos o problema formulado por A28-11.

Figura 5: Problema formulado por A28-11

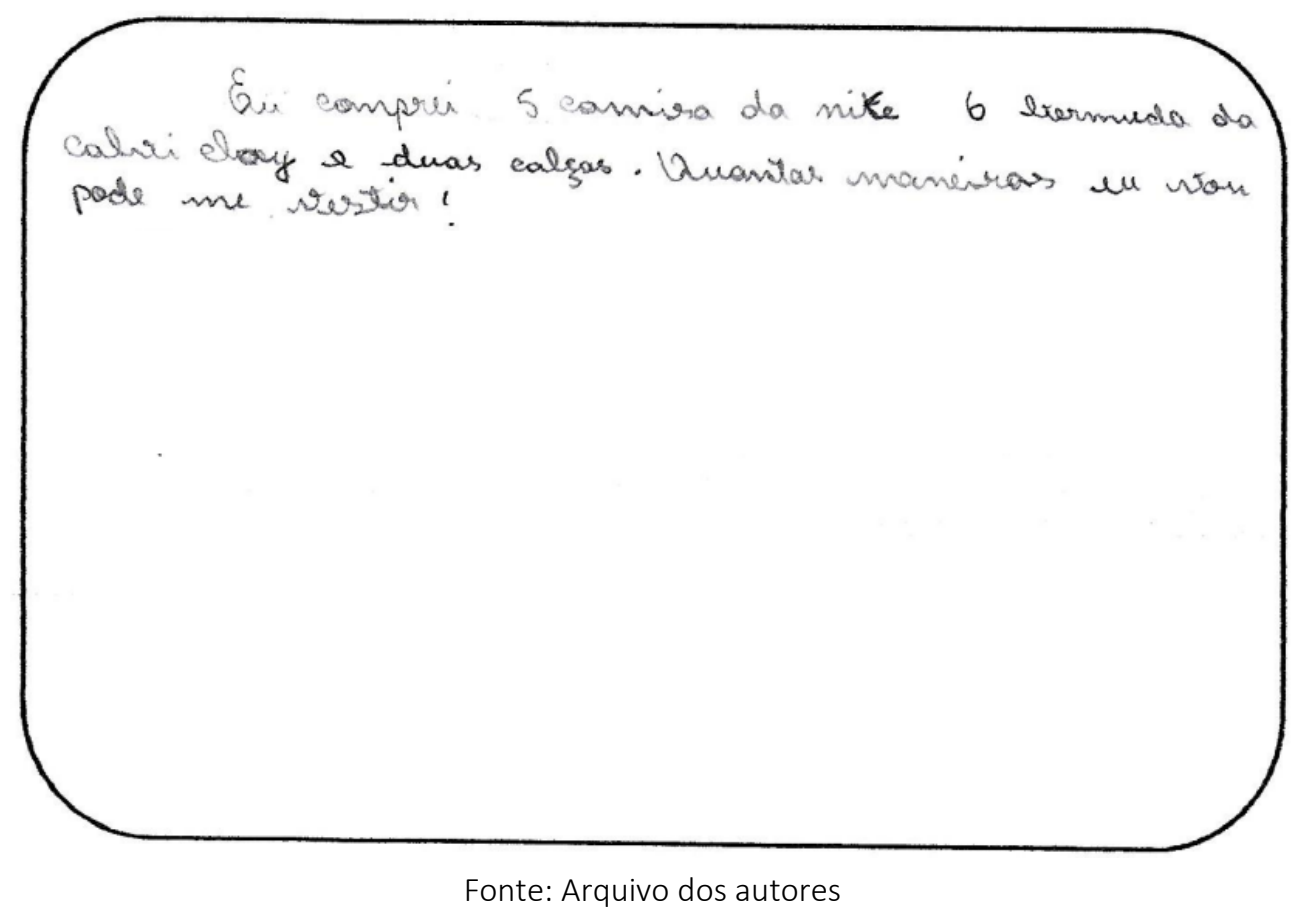

Essa proposta se encaixa na classe de problemas de combinatória, uma vez que a própria pergunta do problema remete a possibilidade de diferentes escolhas, típico do pensamento combinatório. Para Vergnaud (2014), o pensamento combinatório carrega o raciocínio de um exemplo de produto cartesiano, que no problema formulado acima, pode ser traduzido pelo par ordenado das partes superiores (camisas) e inferiores (bermudas e calcas). Assim, nessa lógica, esse problema poderia facilmente ser resolvido realizando a multiplicação $4 \times 6 \times 2=48$ maneiras distintas, mas tal cálculo incluiria a possibilidade de uma pessoa usar uma calça e uma bermuda ao mesmo tempo, o que

\footnotetext{
${ }^{5}$ Estamos considerando como contexto situações cotidianas vividas (contexto real) ou não (contexto imaginário) pelos educandos.
} 


\section{sala \\ de $\oplus$ em \\ aula foco}

- REVISTA ELETRÔNICA

parece um pouco estranho e incomum. Assim, mesmo diante dessa questão, podem existir pessoas que façam essa combinação, o que também não seria um erro.

Segundo Chica (2001), a formulação é um caminho para se desenvolver o espírito crítico, a argumentação e a observação e sugere que sejam feitas intervenções para que os estudantes consigam melhorar a escrita dos seus problemas, e comunicar com clareza o que pretendem. Diante disso, consideramos que a proposta de A28-11 pode gerar questionamentos quanto ao processo resolutivo, pois caberiam duas maneiras de interpretá-lo, considerando ou não o uso de calcas e bermudas concomitantemente.

Seguindo o pensamento de que ou se usa a calça ou a bermuda, poderíamos expressar a resposta por meio de duas multiplicações: uma que resultaria no total de maneiras distintas de se vestir uma camisa e uma calça $(5 \times 2=10)$ e outro no total de maneiras distintas de se vestir uma camisa e uma bermuda ( $5 \times 6=30$ ), totalizando 40 maneiras distintas. Veja que esse total é menor do que o apresentado anteriormente, caso bermudas e calças fossem vestidas ao mesmo tempo.

Considerando o produto cartesiano sugerido por Vergnaud (2014), o conjunto das camisas por $A=\{C 1, C 2, C 3, C 4, C 5\}$, o conjunto das calças por $B=\{C l 1, C l 2\}$ e o conjunto de bermudas por $C=\{B 1, B 2, B 3, B 4, B 5, B 6\}$, teríamos as seguintes representações, totalizando 40 pares ordenados.

B1 B2 B3 B4

B5

\begin{tabular}{l|llllll} 
C1 & $(\mathrm{C} 1, \mathrm{~B} 1)$ & $(\mathrm{C} 1, \mathrm{~B} 2)$ & $(\mathrm{C} 1, \mathrm{~B} 3)$ & $(\mathrm{C} 1, \mathrm{~B} 4)$ & $(\mathrm{C} 1, \mathrm{~B} 5)$ & $(\mathrm{C} 1, \mathrm{~B} 6)$ \\
$\mathrm{C} 2$ & $(\mathrm{C} 2, \mathrm{~B} 1)$ & $(\mathrm{C} 2, \mathrm{~B} 2)$ & $(\mathrm{C} 2, \mathrm{~B} 3)$ & $(\mathrm{C} 2, \mathrm{~B} 4)$ & $(\mathrm{C} 2, \mathrm{~B} 5)$ & $(\mathrm{C} 2, \mathrm{~B} 6)$ \\
$\mathrm{C} 3$ & $(\mathrm{C} 3, \mathrm{~B} 1)$ & $(\mathrm{C} 3, \mathrm{~B} 2)$ & $(\mathrm{C} 3, \mathrm{~B} 3)$ & $(\mathrm{C} 3, \mathrm{~B} 4)$ & $(\mathrm{C} 3, \mathrm{~B} 5)$ & $(\mathrm{C} 3, \mathrm{~B} 6)$ \\
$\mathrm{C} 4$ & $(\mathrm{C} 4, \mathrm{~B} 1)$ & $(\mathrm{C} 4, \mathrm{~B} 2)$ & $(\mathrm{C} 4, \mathrm{~B} 3)$ & $(\mathrm{C} 4, \mathrm{~B} 4)$ & $(\mathrm{C} 4, \mathrm{~B} 5)$ & $(\mathrm{C} 4, \mathrm{~B} 6)$ \\
$\mathrm{C} 5$ & $(\mathrm{C} 5, \mathrm{~B} 1)$ & $(\mathrm{C} 5, \mathrm{~B} 2)$ & $(\mathrm{C} 5, \mathrm{~B} 3)$ & $(\mathrm{C} 5, \mathrm{~B} 4)$ & $(\mathrm{C} 5, \mathrm{~B} 5)$ & $(\mathrm{C} 5, \mathrm{~B} 6)$
\end{tabular}

\begin{tabular}{l|ll}
$\mathrm{C} 1$ & $(\mathrm{C} 1, \mathrm{Cl} 1)$ & $(\mathrm{C} 1, \mathrm{Cl} 2)$ \\
$\mathrm{C} 2$ & $(\mathrm{C} 2, \mathrm{Cl} 1)$ & $(\mathrm{C} 2, \mathrm{Cl} 2)$ \\
$\mathrm{C} 3$ & $(\mathrm{C} 3, \mathrm{Cl} 1)$ & $(\mathrm{C} 3, \mathrm{Cl} 2)$ \\
$\mathrm{C} 4$ & $(\mathrm{C} 4, \mathrm{Cl} 1)$ & $(\mathrm{C} 4, \mathrm{Cl} 2)$ \\
$\mathrm{C} 5$ & $(\mathrm{C} 5, \mathrm{Cl} 1)$ & $(\mathrm{C} 5, \mathrm{Cl} 2)$
\end{tabular}

Evidenciamos que os problemas formulados pelos estudantes, em sua totalidade, abarcavam contextos próximos de suas vidas, por vezes situações já vividas ou que seriam vivenciadas por eles, incluindo pessoas próximas e reais. Assim, defendemos que a formulação de problemas abre espaço para que os estudantes busquem, nas próprias vivências, aplicações e correlações com a 


\section{sala \\ de $\theta$ em \\ aula foco}

matemática, gerando descobertas e motivação em aprender, e que, segundo Chica (2001), não deve acontecer apenas em algumas aulas de matemática, mas ter sua presença contínua perdendo seu caráter de "prática curiosa".

Nos enunciados dos problemas, os contextos foram os mais diversos como, por exemplo, sorveterias, lojas de roupas, pastelarias, aniversários, viagens e, até mesmo, almoço beneficente. Nas Figuras 6 e 7, abaixo, vemos a justificativa de A18-11 e A21-11 com relação à criação de seus problemas.

Figura 6: Justificativa de A18-11

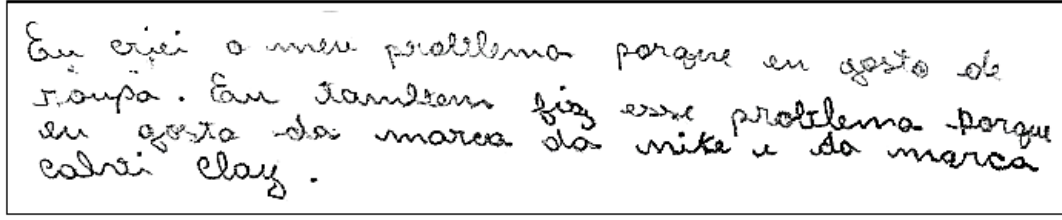

Fonte: Arquivo dos autores

Figura 7: Justificativa de A21-11

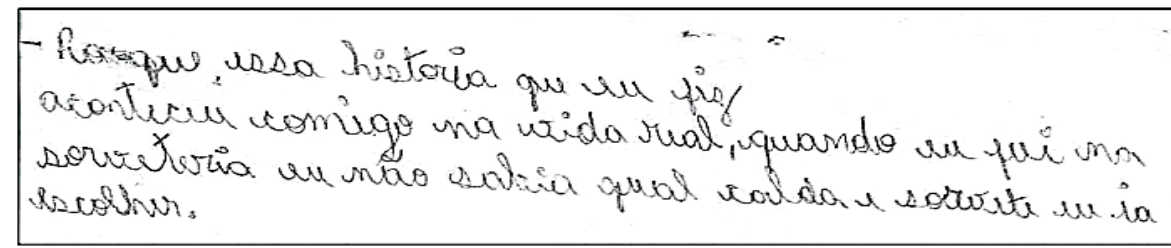

Fonte: Arquivo dos autores

A partir dessas constatações, entendemos que os problemas formulados carregaram motivações pessoais e interesses em descobrir respostas. É nesse sentido que indicamos o trabalho, em sala de aula, a partir desses problemas, pois suas estruturas e soluções podem ser importantes para quem o formulou. 


\section{sala \\ de $\oplus$ - em \\ aula foco}

- REVISTA ELETRÔNICA

\section{CONSIDERAÇÕES FINAIS}

As análises nos levaram a concluir que a proposta de Formulação de Problemas, intitulada "Um passeio à lanchonete", na classe de problemas de combinatória, tem potencial educativo à medida que contribuiu para a prática/processo de formulação de problemas nas aulas de matemática, cujas produções podem ser utilizadas no ensino de multiplicação e divisão no Campo Conceitual Multiplicativo. O trabalho com essas produções pode despertar o interesse dos discentes pela resolução de problemas e entusiasmá-los na investigação, conforme aponta Dante (2009) ao tratar que a resolução dos próprios problemas é um fator motivador na aprendizagem matemática.

Além dessas evidências, reforçamos que os estudantes ainda, no decorrer da aplicação da proposta, encaram a formulação de problemas como algo novo e diferente nas aulas de matemática, apresentando, também, dificuldades no processo de elaboração, o que vem ao encontro das conclusões também encontradas nos estudos de Medeiros e Santiago (2013) e Pinheiro (2013).

Vale salientar, também, que muitos problemas carregaram lacunas que possibilitariam diferentes debates em sala de aula, levando a restruturações para melhor serem caracterizados de pensamento combinatório. Assim, compreendemos que maiores envolvimentos dos estudantes com a formulação de problemas poderiam elevar a qualidade das produções e, consequentemente, desenvolver a criatividade, fator inerente ao processo conforme aponta Silver (1994).

Sendo assim, gostaríamos de ressaltar que a formulação de problemas não vem retirar ou minimizar o dever e o compromisso do professor com a proposição de problemas em sala de aula, mas intensificar e expandir os horizontes do envolvimento dos alunos nas aulas de matemática e na produção de problemas para a sua própria aprendizagem. A formulação de problemas é uma característica fundamental à aprendizagem matemática! 


\section{sala \\ de $\oplus$ - em \\ aula foco}

- REVISTA ELETRÔNICA

\section{REFERÊNCIAS}

ALTOÉ, R. O. Formulação de Problemas do Campo Conceitual Multiplicativo no Ensino Fundamental: uma prática inserida na metodologia de resolução de problemas. 2017. 227f. Dissertação (Mestrado em Educação em Ciências e Matemática) - Programa de Pós-graduação em Educação em Ciências e Matemática. Instituto Federal do Espírito Santo, Vitória, 2017.

ALTOÉ, R. O.; FREITAS, R. C. O. Formulação de Problemas: multiplicação e divisão. Vitória: Instituto Federal de Educação, Ciência e Tecnologia do Espírito Santo, 2017.

ALMOULOUD, S. A.; COUTINHO, C. D. Q. E. S. Engenharia Didática: características e seus usos em trabalhos apresentados no GT-19/ANPEd. Revista Eletrônica de Educação Matemática, Florianópolis, v. 3, n. 1, p. 6277, 2008.

ARTIGUE, M. Engenharia Didática. In: Didática das Matemáticas. Trad. Maria José Figueiredo. Lisboa: Instituto Piaget, p. 193-217, 1996.

CHICA, C. H. Por que formular problemas? In: Ler, escrever e resolver problemas: habilidades básicas para aprender matemática. 1. ed. reimp. São Paulo: Artmed, p. 151-173, 2001.

DANTE, L. R. Formulação e resolução de problemas de matemática: teoria e prática. 1. ed. São Paulo: Ática, 2009.

DINIZ, M. I. Resolução de Problemas e Comunicação. In: Ler, escrever e resolver problemas: habilidades básicas para aprender matemática. 1. ed. reimp. São Paulo: Artmed, p. 89-97, 2001.

MEDEIROS, K. M.; SANTIAGO, M. S. Formulação e resolução de problemas matemáticos na sala de aula: explicitando o intertexto. In: XXIV Seminário de Investigação em Educação Matemática. Braga: APM \& CIEd da Universidade de Minho, p. 583-585, 2013.

MOREIRA, M. A. Teorias de aprendizagem. 2. ed. ampl. reimpr. São Paulo: E.P.U, 2015.

PAIS, L. C. Didática da matemática: uma análise da influência francesa. Belo Horizonte: Autêntica, 2011.

PINHEIRO, S. A criatividade na resolução e formulação de problemas: uma experiência didática numa turma do 5 o ano de escolaridade. 2013. 217f. Dissertação (Mestrado em Educação) - Programa de Especialidade em Didática da Matemática e das Ciências. Instituto Politécnico de Viana do Castelo, Viana de Castelo/PT, 2013.

SILVER, E. A. On mathematical problem posing. In: For the Learning of Mathematical. v. 14, n. 1, p. 19-28, 1994.

VERGNAUD, G. A criança, a matemática e a realidade: problemas do ensino de matemática na escola elementar. Trad. Maria Lucia Faria Moro. 3. ed. rev. Curitiba: Ed. da UFPR, 2014. 